The Relationship of Pleural Manometry with Post-Thoracentesis Chest Radiographic Findings in Malignant Pleural Effusion

Authors: Amit Chopra MD ${ }^{1}$, Marc A. Judson MD ${ }^{1}$, Peter Doelken MD¹, Fabien Maldonado MD², Najib Rahman, D Phil MSc ${ }^{3}$, John T Huggins, MD ${ }^{4}$

1. Department of Medicine, Pulmonary and Critical Care Medicine, Albany Medical Center, NY

2. Department of Medicine, Division of Allergy, pulmonary and Critical Care Medicine, Vanderbilt University Medical Center, Nashville, TN;

3. Oxford Centre for Respiratory Medicine, Oxford Respiratory Trials Unit, University of Oxford, Cambridge, UK

4. Department of Medicine, Division of Pulmonary, Critical Care, Allergy and Sleep Medicine, Medical University of South Carolina, Charleston, SC

Address Correspondence to:

Amit Chopra, MD

Assistant Professor of Medicine

Division of Pulmonary and Critical Care Medicine

Department of Medicine, MC- 91

Albany Medical College

47 New Scotland Avenue

Albany, NY 12208, USA

chopraa1@mail.amc.edu 
Keywords:

Pleural manometry

Malignant pleural effusion

Lung entrapment

Pleurodesis

Pleural elastance

Word Count:

Abstract: 241

Text: 2,273 


\section{Cover Letter:}

\section{Dear Editors of CHEST:}

We are submitting our manuscript titled, "The correlation of pleural manometry with postthoracentesis chest radiographic findings in malignant pleural effusions" for your consideration of publication in Chest. Currently, the placement of an indwelling pleural catheter and chemical pleurodesis are both acceptable strategies for the management of malignant pleural effusions (MPE). Abnormal lung expansion and elevated pleural elastance are both considered contraindications for pleurodesis. However, the frequency of elevated pleural elastance in MPE has not been previously determined. In addition, the presence of increased pleural space elastance may suggest the presence of a significant number of patients with unexpandable lung, which may overall limit pleurodesis success.

Our investigation documents that an elevated pleural elastance is present in roughly $50 \%$ of MPE patients. In addition, we found a discordance between the post-thoracentesis radiograph findings and the pleural manometry findings in terms of identifying contraindications to pleurodesis based on current guidelines. Our observations may suggest that pleural manometry, in addition to the postthoracentesis chest radiograph, may have a complementary role in selecting patients with MPE for accelerated pleurodesis strategy. The data presented may help further facilitate well-designed studies to evaluate pleurodesis outcomes when both pleural manometric findings and post-chest radiography are incorporated into the clinical design. We believe our findings have a scientific and clinical relevance for consideration of publication. We await your thoughtful review.

Sincerely for all the authors, Amit Chopra, MD 


\section{Abstract:}

Introduction: Both elevated pleural elastance $\left(E-P_{E L}\right)$ and radiographic evidence of incomplete lung expansion following thoracentesis have been used to exclude patients with a malignant pleural effusion (MPE) from undergoing pleurodesis. We report a cohort of MPE patients in which complete drainage was attempted with pleural manometry to determine the frequency of E-P $P_{E L}$ and its relationship with the postthoracentesis radiographic findings.

Methods: We identified 70 consecutive MPE patients who underwent therapeutic pleural drainage with pleural manometery. The pressure/volume curves were constructed and analyzed to determine the frequency of $E-P_{E L}$ and the relationship of $P_{E L}$ to the post-thoracentesis chest radiographic findings.

Results: E-P $\mathrm{EL}_{\mathrm{EL}}$ and incomplete lung expansion was identified in 36 of 70 (51.4\%) and 38 of 70 (54\%) patients respectively. Patients with normal $P_{E L}$ had an odds ratio of 6.3 of having complete lung expansion compared to those with an E-PEL $(P=0.0006)$. However, 20 of $70(29 \%)$ of patients demonstrated a discordance between post-procedural chest radiographic findings and the pleural manometry results. Among patients who achieved complete lung expansion on the post-drainage chest radiograph, 9 of $32(28 \%)$ had

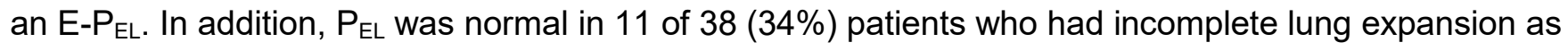
detected by post-thoracentesis chest radiograph.

Conclusions: An E-PEL and incomplete lung expansion post- thoracentesis are frequently observed in MPE patients. Nearly one third of the cohort demonstrated a discordance between the post-procedural chest radiographic findings and pleural manometry results. Our findings suggest that a prospective randomized trial should be done to compare both modalities (chest radiograph and pleural manometry) in predicting pleurodesis outcome. 


\section{Introduction}

Pleurodesis and indwelling pleural catheter (IPC) placement are the acceptable treatment options for the management of malignant pleural effusion (MPE). ${ }^{1}$ In patients with expandable lung, both IPC and chemical pleurodesis are recommended as first line therapy as per current American Thoracic Society guidelines. ${ }^{1}$ Adequate pleural apposition is a prerequisite in order to achieve successful pleurodesis in MPE. The current British Thoracic Society guidelines recommend demonstration of pleural apposition on a chest radiograph following pleural fluid removal as a criterion for pleurodesis in MPE. ${ }^{2}$ A prior study by Lan and colleagues showed that pleurodesis was uniformly unsuccessful in those who had an E-PEL in MPE patients. ${ }^{3}$ While both failure of complete drainage and an E- $\mathrm{P}_{E L}$ approaches are contraindications for pleurodesis, there are currently no data examining the prevalence of E-PEL in patients with MPE who undergo an attempt at complete pleural drainage; in addition, the relationship of the pressure/volume (P/V) curve and the post thoracentesis chest radiograph findings have not previously been explored.

We performed a prospective observational study to compare post-drainage chest radiograph findings with pleural manometric findings in MPE undergoing attempted complete pleural drainage. The goals of this study were: 1) to determine the prevalence of $\mathrm{E}-\mathrm{P}_{\mathrm{EL}}$ in patients with MPE; and 2) to compare pleural manometry findings with post-thoracentesis chest radiographic findings.

\section{Materials and Methods}

We retrospectively reviewed consecutive patients with a diagnosis of MPE based on the positive pleural cytology who underwent an attempt at complete pleural drainage and had concomitant pleural manometry. A post-thoracentesis anteroposterior view chest radiograph was obtained immediately following thoracentesis. Each post-procedural chest radiograph was reviewed independently by a dedicated thoracic radiologist. 
Post-procedural chest radiographs were evaluated for: a) complete lung expansion (CLE-CXR), which was defined as $>90 \%$ pleural apposition on the frontal view; and b) incomplete lung expansion (ILE-CXR), defined as $\leq 90 \%$ pleural apposition; or drainage related pneumothorax (pneumothorax ex vacuo) on a frontal view chest radiograph ${ }^{4}$.

Pleural manometry was performed with an electronic acquisition system and damped water manometer as published previously. ${ }^{5}$ In order to measure pleural pressures and pleural space elastance $P_{E L}$ at the time of thoracentesis, the patient was placed in an upright sitting position with the arms resting on a level surface. The manometer was attached to a 3-way stopcock on the pleural catheter to allow repeated measures of pleural pressure during fluid removal. When using a water manometer, the zero-pressure level was set where the catheter entered the chest wall. The initial mean pleural pressure was measured after approximately $20 \mathrm{ml}$ of pleural fluid was removed. Mean pleural pressure was measured during periods of tidal breathing and assessed over four to five respiratory cycles representing quiet breathing. During subsequent fluid removal, the pleural pressure was measured after each aliquot of 100 to $250 \mathrm{~mL}$ of pleural fluid. Pleural fluid drainage was discontinued if the following conditions occurred: a) the mean pleural pressure declined below $-20 \mathrm{~cm} \mathrm{H} \mathrm{H}_{2} \mathrm{O}$; b) the patient reported significant chest pain; or c) no further pleural fluid could be drained. The pressure/volume $(P / V)$ curves were constructed for analysis and $P_{E L}$ was calculated. The last pleural pressure measurement was considered valid by documenting the presence of fluid on thoracic ultrasound, or at least $50 \mathrm{ml}$ of pleural fluid was removed. E-Pel was defined as the presence of either a monophasic $\mathrm{P} / \mathrm{V}$ curve with a $\mathrm{P}_{\mathrm{EL}}>14.5 \mathrm{~cm} \mathrm{H} \mathrm{H}_{2} \mathrm{O} / \mathrm{L}$, or a biphasic $\mathrm{P} / \mathrm{V}$ curve in which the terminal portion of the biphasic $\mathrm{P} / \mathrm{V}$ curve had a $\mathrm{P}_{\mathrm{EL}}$ of $>14.5 \mathrm{~cm} \mathrm{H} \mathrm{H}_{2} \mathrm{O} / \mathrm{L}^{4}$. A monophasic $\mathrm{P} / \mathrm{V}$ curve with a $\mathrm{P}_{\mathrm{EL}} \leq 14.5 \mathrm{~cm} \mathrm{H} \mathrm{H}_{2} \mathrm{O} \mathrm{L}$ represented normal $\mathrm{P}_{\mathrm{EL} .}{ }^{4}$ Validation of the last mean pleural pressure is necessary since the pleural pressure may be artifactual low because of the local deformation forces around the catheter tip..$^{5-7}$ 
Statistical analysis was performed using SigmaPlot (Systat Software, Inc.; San Jose, Ca) version 11.0. Continuous variables were presented as mean, median with standard deviation, and $5^{\text {th }}-95^{\text {th }}$ percentile range. Categorical variables were expressed as percentages and interquartile ranges. The differences between the two groups were evaluated with either an unpaired t-test or Mann-Whitney rank sum test, depending on the characteristics of the distribution of the variable tested. For categorical data, $2 \times 2$ contingency tables were constructed, and the data was analyzed using a two-tailed Chi-square test. A p value of $<0.05$ was considered statistically significant.

\section{Results}

We identified 70 consecutive patients who had undergone therapeutic thoracentesis and concomitant pleural manometry. The demographics and tumor characteristics of our cohort are shown in Table 1. Fiftyseven of $70(81.4 \%)$ patients had an adenocarcinoma. A non-lung primary was detected in 51 of $70(72.8 \%)$ of the patients. The 70 patients who had undergone therapeutic thoracentesis and concomitant pleural manometry constituted the cohort that we analyzed. Selection of patients undergoing pleural manometry was determined by the capability of the clinician to perform the procedure and not by clinical or radiographic data.

The post-thoracentesis chest radiographs were available in all 70 patients and showed complete expansion in 32 of $70(46 \%)$ while 38 of $70(54 \%)$ had either incomplete drainage in 25 of $70(36 \%)$ or a drainage related pneumothorax in 13 of $70(18 \%)$.

Normal $\mathrm{P}_{\mathrm{EL}}$ was observed in 34 of 70 (49\%) patients. (Table 2) Of these 34 patients, 32 (94\%) had a monophasic P/V curve with $\mathrm{P}_{\mathrm{EL}} \leq 14.5 \mathrm{~cm} \mathrm{H} \mathrm{H}_{2} \mathrm{O} / \mathrm{L}$ (Figure 2a). Two patients with normal lung expansion had an unusual "inverted" biphasic PN curve with an initial high $\mathrm{P}_{\mathrm{EL}}$ and a normal terminal $\mathrm{P}_{\mathrm{EL}}$. This may occur in 
situations where $\mathrm{P}_{\mathrm{EL}}$ is initially transiently elevated because of lobar atelectasis that resolves with pleural fluid removal. For the purposes of our analyses, we interpreted the two patients with the inverted biphasic P/V curves as representing normal $\mathrm{P}_{\mathrm{EL}}$.

Elevated $\mathrm{P}_{E L}$ was detected in 36 of 70 (51\%) (Table 2); Nine of $36(25 \%)$ had a monophasic P/V curve with a $\mathrm{P}_{\mathrm{EL}}>14.5 \mathrm{~cm} \mathrm{H}_{2} \mathrm{O} / \mathrm{L}$ (mean 21.8, SD 4.1; median 20.8, range 18.2-31.6). (Figure 2b) Twenty-seven of 36 (75\%) patients had a biphasic P/V curve with a $\mathrm{P}_{\mathrm{EL}}$ for the initial portion of the curve (E1) $\leq 14.5 \mathrm{~cm} \mathrm{H}_{2} \mathrm{O} / \mathrm{L}$ (mean 8.8, SD 3.1; median 8.6, range 3.3-8.6) and a $\mathrm{P}_{\mathrm{EL}}$ for the terminal portion of the curve $(\mathrm{E} 2)>14.5 \mathrm{~cm}$ $\mathrm{H}_{2} \mathrm{O} / \mathrm{L}$ (mean 41.4. SD 27.9; median 33.3, range 15.3-129.0). (Figure 2c).

There was no statistically significant difference in age, race, gender, tumor origin, or tumor cell type between the normal and the E-PEL group (Table 3); or CLE-CXR and ILE-CXR (Table 4). The mean pleural fluid volume drained was statistically significantly greater $(p=0.04)$ in the normal $P_{E L}$ group $(1589 \mathrm{~mL})$ compared to the E-P $\mathrm{EL}_{\text {group }}(1180 \mathrm{~mL})$.

Figure 1 and Table 5 outline the relationship between the post-thoracentesis chest radiograph findings and pleural manometry results. Patients with normal $\mathrm{P}_{\mathrm{EL}}$ had a significantly statistically higher rate of complete lung expansion on chest radiograph $23 / 34(68 \%)$ compared to those with $E-P_{E L} 9 / 36(25 \%)(P<0.005)$ (Figure 1). Patients with $E-P_{E L}$ had a statistically significantly higher rate $(P=0.002$, ) of ILE-CXR $27 / 70(38.5 \%)$, than those with normal $P_{E L} 11 / 70$ (15.7\%). (Figure 1) Patients with normal $P_{E L}$ had an odds ratio of 6.3 of having CLE-CXR compared to those with an E-PEL $(P=0.0006)$. Concordance between the $P_{E L}$ and postthoracentesis chest radiograph criteria for pleurodesis was found in 50 of 70 (71\%) of cases; whereas, 20 of $70(29 \%)$ patients had a discordance between these two criteria (Table 5). Eleven of 38 (34\%) patients with ILE-CXR had normal $\mathrm{P}_{\mathrm{EL}}$ while 9 of $32(28 \%)$ patients with complete lung expansion had an elevated $\mathrm{P}_{\mathrm{EL}}$. 


\section{Discussion}

In this analysis of 70 patients with MPE who underwent pleural drainage with pleural manometry, the postthoracentesis chest radiographic findings and pleural manometry each identified a contraindication to pleurodesis in approximately $50 \%$ of the cohort.

The prevalence of ILE-CXR was 54\% in our cohort and was higher than previously reported from prior studies, ranging $2 \%$ to $30 \%$. ${ }^{8-10}$ The degree of variability in ILE-CXR across various series may be due to heterogeneity in the accepted degree of pleural apposition $(50 \%-90 \%)$ on the post-drainage chest radiograph to determine chemical pleurodesis eligibility ${ }^{8-15}$. Interestingly, the studies which required higher degree of pleural apposition (>90\%) to define lung expansion had higher prevalence rates of ILE-CXR than studies less rigorous degrees of apposition on chest radiograph. Our higher rate of ILE-CXR compared to previous studies may be explained by our requirement of at least $90 \%$ apposition of visceral and parietal pleura apposition to define adequate pleural fluid drainage.

We found the prevalence of E-PEL in MPE was approximately $50 \%$. If the prevalence of E-PEL with MPE is closer to $50 \%$ as seen in our cohort, the manometry and post-pleural drainage chest radiograph findings reported could explain the low pleurodesis success rates $(<50 \%)$ and suggest a plausible explanation for the lower pleurodesis success rates in the published literature. ${ }^{8914-17}$ To our knowledge, there are no published data available describing the prevalence of $E-P_{E L}$ in MPE patients during an attempt to completely drain a MPE. One prior study demonstrated that pleural manometry findings accurately predict the success of pleurodesis in $\mathrm{MPE}^{3}$. In that study, 14 of $57(25 \%)$ subjects had E-P $\mathrm{EL}_{\mathrm{L}} \cdot \mathrm{A} \mathrm{P}_{\mathrm{EL}}<19 \mathrm{cmH}_{2} \mathrm{O} / \mathrm{L}$ had a $98 \%(42 / 43)$ pleurodesis success rate, whereas those with $\mathrm{P}_{\mathrm{EL}}>19 \mathrm{cmH}_{2} \mathrm{O} / \mathrm{L}$ had $100 \%(14 / 14)$ pleurodesis failure. ${ }^{3}$ However this study was never replicated in a larger study. A major limitation of that study was that $P_{E L}$ was calculated over first $500 \mathrm{ml}$ of pleural fluid drainage and there was lack of evaluation of the entire P/V curve. 
This may represent a cohort of patients with monophasic P/V curve and might have missed patients who have biphasic $P / V$ curve with high terminal $P_{E L}$ and thereby underestimating the frequency of E-PEL. In addition, the follow-up period for pleurodesis success was short and measured only at 1 month by CXR.

Nearly one-third of patients had discordance between post-drainage chest radiograph and pleural manometry findings.. These results suggest that the post-pleural drainage findings on chest radiograph alone are inadequately sensitive and inadequately specific to detect $E-P_{E L}$. Our analysis supports the premise that performing pleural manometry during thoracentesis may provide additional information in terms predicting the outcome of pleurodesis procedures. We believe that comparison of these two criteria with pleurodesis outcomes will need to be addressed.

The explanation for the discordance between these two criteria for pleurodesis of MPE patients remains unclear. The post-thoracentesis chest radiograph may show incomplete lung expansion while the $\mathrm{P}_{\mathrm{EL}}$ is normal because either: a) drainage was prematurely stopped due to a mechanism other than unexpandable lung, such as presence of pleural adhesions not allowing complete drainage or chest pain due to catheter irritating diaphragm; or b) the $\mathrm{P}_{\mathrm{EL}}$ may be falsely normal in cases of drainage related pneumothorax. In our study, drainage related pneumothorax was present roughly in one fifth of the cases, but approximately one third of patients had drainage related pneumothorax had a normal $\mathrm{P}_{\mathrm{EL}}$. Proposed mechanism for drainage related pneumothorax may result of air entry from the lung into the pleural space from the development of a pressure dependent alveolar-pleural fistula. ${ }^{4}$ Air-leaks through these fistulas may elevate the pleural pressure into normal physiologic ranges, resulting in "pseudo-normalization" of $\mathrm{P}_{\mathrm{EL}}$ and pressure/volume curves. Additionally, the presence of an air entry into the drainage system may interfere with an accurate reading of pleural pressures. 
Our study has several limitations. First, the study cohort consisted of patients from a single center and may not be generalizable to all MPE patients. Second, we did not explore the mechanisms responsible for the discordance between the ILE-CXR and E-PEL results in our cohort. Although this may be a useful exercise in determining the eligibility for pleurodesis in MPE who demonstrate a discordance, this could not be performed in our retrospective analysis. We hypothesize that in future prospective studies that incorporate the success rate of pleurodesis, distinguishing the cause for the discordance may be impactful in establishing more reliable eligibility criteria for pleurodesis. Lastly, our assessment of lung expansion after pleural drainage was rudimentary as we relied on the post-thoracentesis chest radiographs alone; however, such an assessment is similar to prior studies.

\section{Conclusion}

The present investigation suggests that $50 \%$ of patients with MPE have an abnormality in lung expansion as detected by pleural manometry and chest radiography. Incomplete lung expansion on post- thoracentesis chest radiograph and E-PEL are both considered as a contraindication to pleurodesis. However, we found a significant discordance between these two criteria. These results suggest that pleural manometry may have role in addition to the post-thoracentesis chest radiograph in selecting patients for pleurodesis; however, confirmation of this conjecture would require a similar study to ours plus an analysis of pleurodesis outcomes. 
Table 1: Demographics and tumor type of patients with malignant pleural effusion undergoing thoracentesis with pleural manometry $(\mathrm{N}=70)$

\section{Age -mean, median(range) years}

\section{Ethnicity}

White

Black

\section{Gender \\ Male}

Female

Tumor origin

Lung

Non-lung
$59,61(37-78)$

$42(60 \%)$

$28(40 \%)$
$19(27 \%)$

$51(73 \%)$

$19(27 \%)$

$51(73 \%)$ 
Tumor cell type

Adenocarcinoma

Non-adenocarcinoma
$57(81 \%)$

$13(19 \%)$

Table 3: Comparison of the demographic data, pleural fluid effusion size, tumor origin, and tumor cell type between the normal and elevated $\mathrm{P}_{\mathrm{EL}}{ }^{*}$ group

\begin{tabular}{|c|c|c|c|}
\hline & Normal $P_{E L}$ & Elevated $P_{E L}$ & $P$ value \\
\hline Age -mean, median(range) years & $59,61(37-78)$ & $64,64(44-84)$ & 0.14 \\
\hline $\begin{array}{l}\text { Ethnicity } \\
\% \text { white } \\
\% \text { Black }\end{array}$ & $\begin{array}{l}65 \\
35\end{array}$ & $\begin{array}{l}56 \\
44\end{array}$ & 0.46 \\
\hline $\begin{array}{l}\text { Gender } \\
\text { \%male } \\
\text { \%female }\end{array}$ & $\begin{array}{l}29 \\
71\end{array}$ & $\begin{array}{l}25 \\
75\end{array}$ & 0.79 \\
\hline $\begin{array}{l}\text { Tumor origin } \\
\text { \%lung } \\
\text { \%non-lung }\end{array}$ & $\begin{array}{l}21 \\
79\end{array}$ & $\begin{array}{l}33 \\
67\end{array}$ & 0.29 \\
\hline $\begin{array}{l}\text { Tumor cell type } \\
\text { \% adenocarcinoma } \\
\% \text { non-adenocarcinoma }\end{array}$ & $\begin{array}{l}85 \\
15\end{array}$ & $\begin{array}{l}78 \\
22\end{array}$ & 0.54 \\
\hline Pleural fluid removed (MI) & $1589,1510(733-2509)$ & $1180,1088(500-2280)$ & 0.04 \\
\hline
\end{tabular}

${ }^{*} \mathrm{P}_{\mathrm{EL}}=$ Pleural elastance

Table 4: Comparison of the demographic data, pleural fluid effusion size, tumor origin, and tumor cell type between the complete lung expansion and incomplete lung expansion

\begin{tabular}{|l|l|l|l|}
\hline & CLE $^{*}$ & ILE $^{* *}$ & P value \\
\hline $\begin{array}{l}\text { Age -mean, median(range) years } \\
\text { Ethnicity }\end{array}$ & $62,64(38-79)$ & $61,62(36-90)$ & 0.80 \\
\hline $\begin{array}{l}\text { \% white } \\
\% \text { Black }\end{array}$ & 53 & 66 & 0.27 \\
\hline $\begin{array}{l}\text { Gender } \\
\text { \%male }\end{array}$ & 47 & 34 & \\
\%female & 31 & 24 & 0.51 \\
\hline $\begin{array}{l}\text { Tumor origin } \\
\text { \%lung }\end{array}$ & 69 & 76 & \\
\%non-lung & 34 & 29 & 0.65 \\
\hline $\begin{array}{l}\text { Tumor cell type } \\
\text { \% adenocarcinoma }\end{array}$ & 66 & 71 & \\
\hline \%non-adenocarcinoma & 84 & 81 & 0.74 \\
\hline
\end{tabular}


* CLE = Complete lung expansion

** ILE= Incomplete lung expansion

Table 5 Post-drainage chest radiograph with respect to pleural manometry findings $(\mathrm{N}=70)$

Chest radiograph findings

\section{Normal $P_{E L}$ $(\mathrm{N}=34)$}

Complete lung expansion

Incomplete lung expansion

${ }^{*} \mathrm{P}_{\mathrm{EL}}=$ Pleural elastance

\section{Elevated $\mathrm{P}_{\mathrm{EL}}$} $(\mathrm{N}=36)$

9

27

Figure Legends:

Figure 1: Distribution of Post-drainage chest radiograph with respect to pleural manometry findings

Figure 2a: Monophasic pressure/volume curves with $\mathrm{P}_{\mathrm{EL}}<14.5 \mathrm{~cm} \mathrm{H} \mathrm{H}_{2} \mathrm{O} / \mathrm{L}$

Figure 2b: Monophasic pressure/volume curves with a $\mathrm{P}_{\mathrm{EL}}>14.5 \mathrm{~cm} \mathrm{H} \mathrm{H}_{2} \mathrm{O} / \mathrm{L}$

Figure 2c: Biphasic pressure/volume curves with an initial $\mathrm{P}_{\mathrm{EL}} \leq 14.5 \mathrm{~cm} \mathrm{H} \mathrm{H}_{2} \mathrm{O} / \mathrm{L}$ and a terminal $\mathrm{P}_{\mathrm{EL}}>14.5 \mathrm{~cm}$ $\mathrm{H}_{2} \mathrm{O} / \mathrm{L}$

Conflicts of Interest: MAJ: consultant for Biogen; Institution grant support from Novartis, Mallinckrodt pharmaceuticals. JH: Consultant/Advisory Boards: IBIOS [IPF]; Roche/Genentech [IPF (Nintedanib)]; Boehringer Ingelheim [IPF (Pirfenidone)]. FM: unrestricted research grant from Centurion. AC: none 


\section{Contribution of authors individually.}

$\mathrm{JHT}$ is the guarantor of the paper and takes responsibility for the integrity of the work as a whole, from inception to published article. All authors contributed to the writing of the manuscript.

\section{Acknowledgements}

We would like to acknowledge the contributions of Dr Steven A. Sahn for his valuable contribution to this paper.

\section{References}

1. Feller-Kopman DJ, Reddy CB, DeCamp MM, et al. Management of Malignant Pleural Effusions. An Official ATS/STS/STR Clinical Practice Guideline. American journal of respiratory and critical care medicine 2018;198(7):839-49.

2. Roberts ME, Neville E, Berrisford RG, et al. Management of a malignant pleural effusion: British Thoracic Society Pleural Disease Guideline 2010. Thorax 2010;65 Suppl 2:ii32-40.

3. Lan RS, Lo SK, Chuang ML, et al. Elastance of the pleural space: a predictor for the outcome of pleurodesis in patients with malignant pleural effusion. Annals of internal medicine 1997;126(10):76874.

4. Heidecker J, Huggins JT, Sahn SA, et al. Pathophysiology of pneumothorax following ultrasound-guided thoracentesis. Chest 2006;130(4):1173-84.

5. Doelken P, Huggins JT, Pastis NJ, et al. Pleural manometry: technique and clinical implications. Chest 2004;126(6):1764-9.

6. Agostoni E. Mechanics of the pleural space. Physiological reviews 1972;52(1):57-128.

7. Lai-Fook SJ. Pleural mechanics and fluid exchange. Physiological reviews 2004;84(2):385-410.

8. Davies HE, Mishra EK, Kahan BC, et al. Effect of an indwelling pleural catheter vs chest tube and talc pleurodesis for relieving dyspnea in patients with malignant pleural effusion: the TIME2 randomized controlled trial. Jama 2012;307(22):2383-9.

9. Thomas R, Fysh ETH, Smith NA, et al. Effect of an Indwelling Pleural Catheter vs Talc Pleurodesis on Hospitalization Days in Patients With Malignant Pleural Effusion: The AMPLE Randomized Clinical Trial. Jama 2017;318(19):1903-12.

10. Dresler CM, Olak J, Herndon JE, 2nd, et al. Phase III intergroup study of talc poudrage vs talc slurry sclerosis for malignant pleural effusion. Chest 2005;127(3):909-15. 
11. Robinson LA, Fleming WH, Galbraith TA. Intrapleural doxycycline control of malignant pleural effusions. The Annals of thoracic surgery 1993;55(5):1115-21; discussion 21-2.

12. Kennedy L, Rusch VW, Strange C, et al. Pleurodesis using talc slurry. Chest 1994;106(2):342-6.

13. Villanueva AG, Gray AW, Jr., Shahian DM, et al. Efficacy of short term versus long term tube thoracostomy drainage before tetracycline pleurodesis in the treatment of malignant pleural effusions. Thorax 1994;49(1):23-5.

14. Putnam JB, Jr., Light RW, Rodriguez RM, et al. A randomized comparison of indwelling pleural catheter and doxycycline pleurodesis in the management of malignant pleural effusions. Cancer 1999;86(10):1992-9.

15. Bhatnagar R, Keenan EK, Morley AJ, et al. Outpatient Talc Administration by Indwelling Pleural Catheter for Malignant Effusion. The New England journal of medicine 2018;378(14):1313-22.

16. Van Meter ME, McKee KY, Kohlwes RJ. Efficacy and safety of tunneled pleural catheters in adults with malignant pleural effusions: a systematic review. Journal of general internal medicine 2011;26(1):706.

17. Wahidi MM, Reddy C, Yarmus L, et al. Randomized Trial of Pleural Fluid Drainage Frequency in Patients with Malignant Pleural Effusions. The ASAP Trial. American journal of respiratory and critical care medicine 2017;195(8):1050-57. 